\title{
Rule Based Expert System for Monitoring Real Time Drug Supply in Hospital Using Radio Frequency Identification Technology
}

\author{
Galih Driandanu $^{1 *}$, Bayu Surarso $^{1}$, and Suryono ${ }^{1}$ \\ ${ }^{1}$ Master in Information System, School of Postgraduate Studies, Diponegoro University, Semarang - Indonesia
}

\begin{abstract}
A radio frequency identification (RFID) has obtained increasing attention with the emergence of various applications. This study aims to examine the implementation of rule based expert system supported by RFID technology into a monitoring information system of drug supply in a hospital. This research facilitates in monitoring the real time drug supply by using data sample from the hospital pharmacy. This system able to identify and count the number of drug and provide warning and report in real time. the conclusion is the rule based expert system and RFID technology can facilitate the performance in monitoring the drug supply quickly and precisely.
\end{abstract}

\section{Introduction}

Rule Based Expert System is a branch of artificial intelligence that was developed in 1960 by Newl and Simon. The name was derived from the knowledgebased expert system, in which the expert knowledge entered into a computer to resolve the problems. The expert system is a knowledge - based programme that provides expert-level solutions in solving specific problems [1]. The use of Rule Based Expert System becomes widespread increasingly, such as in mineral water identification which supported by visual basic for the implementation and Microsoft access for creating the database. This is driven by the insufficient mineral water experts who give the knowledge in the water resource area. Mineral water knowledge expert system can help cater the knowledge in the water resource areas [2]. The purpose of Rule Based Expert System application is providing fast response with the given rules based on the experts in their fields [3]. India has used the technology in handling crimes against women for better judiciary. The technology which combined with the Rule Based Expert System method helps in giving decisions based on the rules given to the legal experts system which matched by entering the data [4]. Judicial problem solution in India which makes use of Rule Based Expert System encourages the writer to develop in the pharmacy field by utilizing this same method for monitoring drug supplies supported by Radio Frequency Identification technology or known as RFID.

The RFID technology is used for system optimization and shrinkage control. Unlike barcode technology, RFID in pharmacy enables giving accurate and real-time information. Besides, RFID also has a bigger storage capacity compared to the barcodes. Counterfeiting is easier to do in this technology because the barcode is easily duplicated. While, information stored in RFID has been encrypted, therefore it makes more difficult to counterfeit the information. RFID also has better resistance than barcode (5).

The use of Rule Based Expert System and RFID technology will help the process of monitoring the realtime drug supply. The system which supported by RFID technology can ease the drug supply calculation manually. Besides, this technology also has the expert knowledge that was put into the system. Hence, it facilitates in monitoring the drug supply in a hospital obviously.

Rule Based Expert System compiled with the formula 1.1 as follows:

$$
\begin{gathered}
\text { R1 : If ( stock free }>\text { Safety stock ) Then } \\
\text { : safe stock order }
\end{gathered}
$$

R2 : If ( stock free <= Safety Stok) Then

$$
\text { : unsafe stock order }
$$

The current stock is obtained from the existing ones in the pharmaceutical warehouse in a hospital. While, for the safety stock gained from the calculation containing some parameters, in which the first are lead time, drug usage in a hospital and also service level. The free stock is generated from the current inventory variable in the warehouse minus the ordering value. The secure and insecure messages status will be formed by comparing between the free stock and safety stock.

The status determination of the service level in a company is expressed as the percentage in each company itself, while the service factor used as a multiplier with the standard deviation to calculate a specific quantity to meet the specified service level. The Excel NORMSINV function can be used for converting the service level percentage to the service factor. Its percentage is shown in Table 1 [6]. 
Tabel 1. Service factor based on service level

\begin{tabular}{cccccc}
\hline No. & $\begin{array}{c}\text { Service } \\
\text { Level }\end{array}$ & $\begin{array}{c}\text { Service } \\
\text { Factor }\end{array}$ & No. & $\begin{array}{c}\text { Service } \\
\text { Level }\end{array}$ & $\begin{array}{c}\text { Service } \\
\text { Factor }\end{array}$ \\
\hline 1 & $50.00 \%$ & 0 & 17 & $90.00 \%$ & 1.28 \\
2 & $55.00 \%$ & 0.13 & 18 & $91.00 \%$ & 1.34 \\
3 & $60.00 \%$ & 0.25 & 19 & $92.00 \%$ & 1.41 \\
4 & $65.00 \%$ & 0.39 & 20 & $93.00 \%$ & 1.48 \\
5 & $70.00 \%$ & 0.52 & 21 & $94.00 \%$ & 1.55 \\
6 & $75.00 \%$ & 0.67 & 22 & $95.00 \%$ & 1.64 \\
7 & $80.00 \%$ & 0.84 & 23 & $96.00 \%$ & 1.75 \\
8 & $81.00 \%$ & 0.88 & 24 & $97.00 \%$ & 1.88 \\
9 & $82.00 \%$ & 0.92 & 25 & $98.00 \%$ & 2.05 \\
10 & $83.00 \%$ & 0.95 & 26 & $99.00 \%$ & 2.33 \\
11 & $84.00 \%$ & 0.99 & 27 & $99.50 \%$ & 2.58 \\
12 & $85.00 \%$ & 1.04 & 28 & $99.60 \%$ & 2.65 \\
13 & $86.00 \%$ & 1.08 & 29 & $99.70 \%$ & 2.75 \\
14 & $87.00 \%$ & 1.13 & 30 & $99.80 \%$ & 2.88 \\
15 & $88.00 \%$ & 1.17 & 31 & $99.90 \%$ & 3.90 \\
16 & $89.00 \%$ & 1.23 & 32 & $99.99 \%$ & 3.72 \\
\hline
\end{tabular}

A company that has implemented safety stock is Danfoss company by entering 4.247 products as the research material to prove the safety stock method can decrease the cost up to $12 \%$. The safety stock calculation conducted by Danfoss company as follows [7] :

a. Computing the forecast deviation for each month

b. Squaring each deviation

c. Computing the standard deviation by the formula shown in equation (1) which $\mathrm{N}$ is the sum of data and $\sigma$ is standard deviation, $\mathrm{d} 1$ is the usage of $-\mathrm{i}$ and $d$ is the usage average.

$$
\sigma=\sqrt{\frac{\sum_{i=1}^{N}\left(d_{1}-d\right)^{2}}{N-1}}
$$

d. Computing the safety stock shown in formula (2) where SS is the safety stock, $z$ is the value based on the service level and LT means the lead time

$$
\mathrm{SS}=z \sqrt{L T \cdot \sigma^{2}}
$$

The safety stock model can be applied in the supply chain to minimize the production cost, transportation and stock supply. It is done because consumer demand which based on the date is changing frequently. This model implements the objectivity function with the procedures applied to the intel dual core 3.0 Ghz and $8 \mathrm{~Gb}$ memory PCs supported by VB.Net software whose it results can be exported into the spreadsheet [8].

\section{The Problem}

The increasing need of drugs nowadays makes the drug supply in a hospital being concerned. It is also triggered by the increasing number of people which contrasts with the good quality of life. Besides, drugs is the biggest income in the hospital which is very simple to calculate the profits gained each month. The drug turnover amount in the hospital reaches $50 \%-60 \%$ of the entire hospital budget. Besides being the biggest income in the hospital, drugs are also something that is needed by the patients. Therefore, the supply must be maintained so that there is no delay in giving the drugs to the patients whom needed [9]. Regular monitoring can be done in order to avoid the delay in the required drug supplies. During this time, the drug supply relies on the pharmacists who check regularly. On the manual checks, miscalculations are often happened due to the officers' limitation such as inaccurate or miscalculate count.

\section{The Idea for Solution}

The main proposed idea is illustrated in Figure 1 which consists of three main parts: input, process, and output.

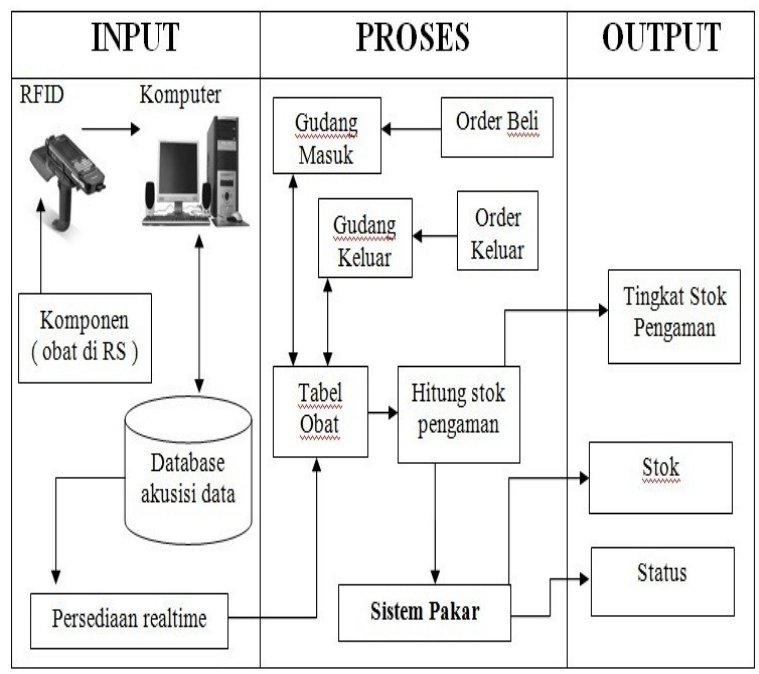

Figure 1 Drug Monitoring System Design

RFID technology is required in the INPUT to obtain, collect and prepare the data, until process to produce the data needed that is identifying the amount of the drug supplies. For example, RFID technology reading the RFID tag that has already installed in the drug wrapping so that it will get the drug data which includes the name, the number and also the supplier of the drug.

The next is the PROCESS section. This section processes the drug data which already received from the input section. The process section will manage the drug by calculating the supply or the minimum limit. By identifying the supply processed for entering into the warehouse that will increase the amount or processed for leaving the warehouse which will reduce the amount of the drug supply. The expert system in this system is used to avoid the void of the drug supply due to being late in ordering the drug to suppliers. The system will facilitate the process of monitoring the drug supply. The decision of making the minimum limit of the drug supply can be done only by the pharmacists who have the specific skill. The rules which are from the pharmaceutical experts are embedded into the system so that the drug monitoring process becomes real time. Therefore, there is no need to wait for the pharmacists to come for calculating the drug supply that are often happened within a drug period. 
The next part is the OUTPUT section. This section provides the result consists of the amount, the status and the minimum quantity of the drug supply. The drug supply status obtained from the rules from the experts as in the formula (1.1), while for the minimum quantity taken from the formula (2) which is the calculation between the service level, lead time and the standard deviation. Based on the calculation and the rules from the experts, this system provides the minimum, the status, and the amount of the drug supply.

\section{System Implementation}

The implementation of the system is carried out in accordance with the design on the rule based expert system for monitoring the drug supply as seen in the figure 1.1. The system has five inputs and four processes to create the transaction report and the safety stock level and the safe or insecure status of the drug supply. The five inputs include the supplier, the drug master, the poly master, the rule based master and the service level input. Four processes that include drug ordering process to the supplier, drug entering process to the warehouse from the supplier, drug ordering process from the poly to the warehouse to deliver the drug needed and the last one is drug recording process from the warehouse to the poly which order some drugs needed.

The generated output in this drug monitoring system are the drug master report, the drug ordering report to the supplier, the drug report which going to the warehouse, the drug ordering report ordered by the poly to the warehouse, the drug report from the warehouse to the ordered poly and the final output is the safety stock report.

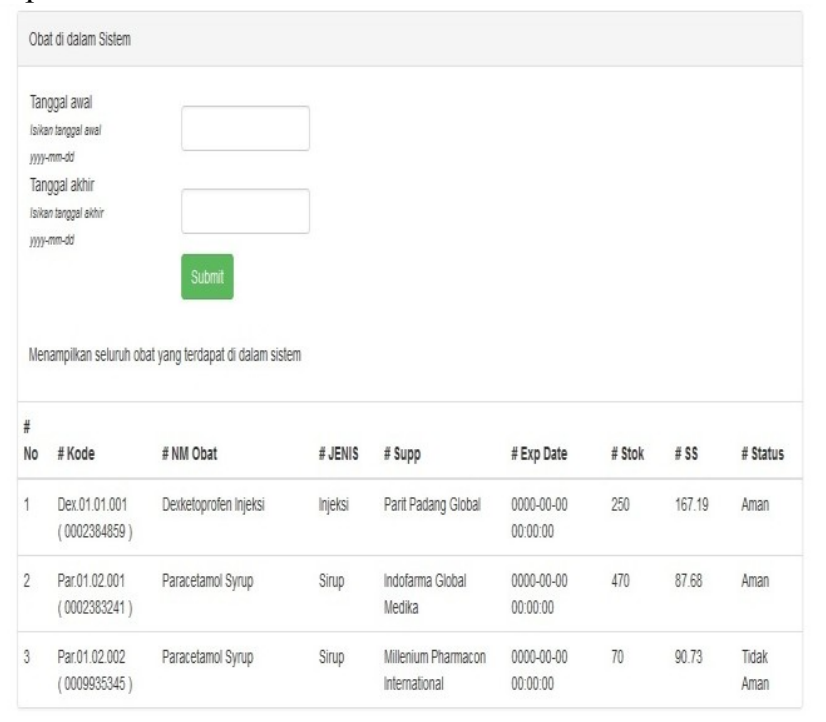

Fig. 2. safety stock report

The safety stock report is the main result from this system that provides the drug supply which can be monitored in real time by providing the data results in the form of the quantity, the minimum quantity and also the safe or unsafe status of the drug supply at that time as in Figure 2.

\section{Discussion}

The implementation of Rule Based Expert System for monitoring the real time drug supply by using rfid technology is a designed system to assist the process of the drug hospital warehouse. Hence, it is expected that the drug needed is already available and there is no vacuum of drug stocks due to manually calculation which causes miscalculation or misinformation of the available stock. The drug monitoring system can be accessed by online. It becomes an added value since for monitoring and deciding new policy of the drug supply can be done everywhere. This system will facilitate the process of monitoring the drug supply from the pharmaceutical staffs until its director who has the right access in the monitoring system. Besides, this monitoring system is a real-time system. The process of the drug supply will be seen directly and at that moment without waiting for the records which done in every single period to find out the remaining stock from the warehouse. This system has the ability of pharmaceutical expert to determine the status of the drug supply. The expert knowledge is applied in this system by providing the experts' decision on the drug supply status, either the stock is safe or unsafe. Therefore the drug should be ordered to the supplier so that the drug void wont be happened since it will be fatal for the patients who need the drug.

The study as in figure 4.1 uses sample data that are three kinds of drugs from different suppliers; dexketoprofen (injection) from the Parit Padang Global, paracetamol syrup from Indofarma Global Medika and paracetamol syrup from Millenium Pharmacon International. Besides, the safety stock calculation done from April 2016 until July 2016 with the service level $75 \%$ which had service factor value 0.67 from the hospital policy.

Information obtained from monitoring of the drug supply at the end July 2016 with 14days leadtime on each drug such as dexketoprofen injection from Parit Padang Global with the code dex.01.01.001 has the safety stock level of 167 tablets with the remaining stock 250 tablets. The rule based expert system of this drug is if it is less from $30 \%$ of the safety stock, the status of this drug will be unsafe. While, the recent stock is still more that $30 \%$ of the drug safety stock so the status of dexketoprofen injection from the Parit Padang Global supplier is safe.

Paracetamol syrup from the Indofarma Global Medika supplier with the code par.01.02.001 has the safety stock level from the calculation in formula 2.2 with the sevice level $75 \%$ which has service factor value 0.67 and 14days leadtime so that the safety stock produced is 87 tablets with the available stock 470 tablets. The rule based expert system of this drug is if the drug stock less than $50 \%$ will be given unsafe status. In fact, the available drug stock is still more than $50 \%$ of the safety stock, so the paracetamol syrup from the Indofarma Global Medika supplier is safe.

For Paracetamol syrup from the Millenium Pharmacon International supplier with the code par.01.02.002 001 has the safety stock level from the 
calculation in formula 2.2 with the sevice level $75 \%$ which has service factor value 0.67 and 14days leadtime. Therefore the safety stock produced is 90tablets with the available stock 70 tablets. The rule based expert system of this drug is if the drug stock less than $30 \%$ of the safety stock will be given unsafe status. In fact, the available drug stock is less than $30 \%$ of the safety stock, so the paracetamol syrup from the Millenium Pharmacon International supplier is unsafe.

\section{Conclusion and further research}

After discussing Rule Based Expert System in monitoring the real time drug supply in the hospital using radio frequency identification technology, can be inferred that this system :

1. Facilitate the hospital in providing the drug supply information

2. Facilitate the pharmacy in monitoring the drug supply both in the warehouse and in the poly of the hospital itself.

3. Facilitate the drug data collection

4. Facilitate in deciding the order time to the supplier when the drug is in short supply.

For the further development of Rule Based Expert System in monitoring the real time drug supply in the hospital using radio frequency identification technology research, the writer gives some suggestions to help the hospitals and also the researchers, namely:

1. The need of additional computer equipment to support this system so that it can works as expected

2. The need of assistance and training to optimize the computers uses so that it can run properly and quickly.

\section{Acknowledgements}

Galih Driandanu thanked to Mr. Bayu Suroso and $\mathrm{Mr}$ Suryono who has guided in this research. As well as the RSUD K.R.M.T Wongsonegoro team who willing to help and provide the drug sample data needed in this study.

\section{References}

1. Luger, George F. and Stubblefield, William A, $A I$ : Structure And Strategic For Complex Problem Solving, 2nd edition, (1993)

2. I.O, Folorunso., O.C. Abikoye, R.G. Jimoh, and K.S. Raji, Journal of Emerging Trends in Computing and Information Sciences, vol. 3 no. 2 , $205-210,(2012)$

3. R. Keller, Prentice Hall, Englewood Clifs, N.J, (1988)

4. J.S. Jadhav, K.M. Nalawade, and M.M. Bapat, In Indian Judicial System, IOSR Journal Of Humanities And Social Science, vol.16 no. 6, 1922, (2013).

5. Cakici, O. Engin, H. Groenevelt, and Decision Support Systems, 51, 842-852, (2011)

6. O. Celik, school of industrial engineering and telecommunication university of Cantabria, (2013)

7. L.F. Tratar, 2009, economic and bussiness review, vol. 11 no.2, 109-117, (2009)

8. K. Funaki, 2010. int. J. Production Economics .135, 4 - 13, (2010)

9. L. Trisnantoro. Aspek Strategi Manajemen Rumah Sakit. Yogyakarta: Penerbit Andi, (2005) 